\title{
O ENSINO DA LÍNGUA JAPONESA NO AMAZONAS
}

\author{
Michele Eduarda Brasil de Sá \\ Ken Nishikido ${ }^{2}$
}

\begin{abstract}
Resumo: O presente artigo baseia-se nos resultados da pesquisa intitulada "História do ensino de língua japonesa no Amazonas", inscrita no Programa Institucional de Bolsas de Iniciação Científica (PIBIC) da Universidade Federal do Amazonas no período 2011-2012. O objetivo da pesquisa é traçar uma cronologia das atividades de ensino da língua japonesa no Amazonas, baseada na própria história da imigração japonesa para o Estado.
\end{abstract}

Palavras-chave: ensino da língua japonesa; imigração japonesa; Amazonas.

Abstract: This article is based on the results of a research entitled "History of Japanese language education in Amazonas", registered in the Institutional Program of Scientific Initiation Scholarships (PIBIC) of the Federal University of Amazonas during 2011-2012. The aim of the research is to trace a chronology of Japanese language teaching in Amazonas, based on the history of Japanese immigration to the state.

Keywords: japanese language teaching; japanese immigration; Amazonas.

\section{Introdução}

No ano de 2011, teve início o curso de Licenciatura Plena em Língua e Literatura Japonesa da Universidade Federal do Amazonas (UFAM), atualmente o único curso de graduação em Língua Japonesa do norte do país. Vários foram os fatores que levaram à demanda por um curso desta natureza na UFAM, dentre

1. Professor Adjunto da Faculdade de Letras da Universidade Federal do Rio de Janeiro (UFRJ) em lotação provisória na Universidade Federal do Amazonas (UFAM), orientadora do PIBIC "História do ensino de língua japonesa no Amazonas" (2011-2012).

2. Presidente da Associação Nipo-brasileira da Amazônia Ocidental (NIPPAKU), orientando do PIBIC "História do ensino de língua japonesa no Amazonas" (2011-2012). 
os quais destacamos a presença numerosa de descendentes de japoneses no Estado do Amazonas e o crescente interesse pela língua e pela cultura japonesa, fenômeno que pode ser testemunhado também em outras regiões do Brasil. Da presença dos descendentes, infere-se a criação de espaços de aprendizagem da língua japonesa; do aumento do interesse pela língua e pela cultura japonesa, infere-se o crescimento destes espaços.

Por este motivo, é necessário que se estude o percurso do ensino da língua japonesa no Amazonas, partindo do processo de imigração japonesa no Estado e levantando dados a respeito das instituições que existem atualmente. O presente artigo é o resultado do projeto de pesquisa intitulado "História do ensino da língua japonesa no Amazonas", inscrito no Programa Institucional de Bolsas de Iniciação Científica - PIBIC da UFAM e iniciado em agosto de 2011.

Com a proliferação dos cursos de língua japonesa em Manaus, uma preocupação se levanta: a necessidade de registrar a história do ensino de língua japonesa desde o momento inicial da presença japonesa no Estado. Tal necessidade é a justificativa desta pesquisa. Como perguntas, podemos pensar em: Quem estudava? Onde estudava? Que materiais eram utilizados? O que mudou hoje? Qual a duração dos cursos? Quantos cursos existem hoje em Manaus? Quantos em outros municípios do Amazonas? Estas perguntas e outras relacionadas nortearam este trabalho. Sabe-se que a maioria dos cursos de japonês pode se enquadrar na categoria de "extracurriculares", na terminologia usada por Morales (2008, p. 138), como o próprio curso oferecido pela Associação Nipo-brasileira da Amazônia Ocidental, ou pelos cursos que antes ofereciam apenas idiomas como inglês e espanhol (mas que agora investem também na língua japonesa), como ALPS e FUCAPI, por exemplo. Contudo, não se pode limitar a análise a estes exemplos. Existe em Manaus a Escola Estadual Josephina de Melo, que oferece japonês como opção de língua estrangeira em seu currículo. A partir de 2011, com o início do curso de graduação em Letras - Japonês da Universidade Federal do Amazonas (UFAM), há mais um local de aprendizagem da língua, mas cuja finalidade e orientação são distintas das instituições que integram a maioria (levando-se em conta o tripé ensino-pesquisa-extensão).

Antes de pensar sobre o ensino de uma determinada língua, é válido - se não imprescindível - pensar a respeito da história e também da cultura do país de onde tal língua se origina. No caso da língua japonesa, sendo o Japão um país de cultura milenar e seu povo comprometido com a manutenção de suas tradições, é natural que a língua seja ensinada em casa, falada em família e em comunidade. Como diz Sakurai (2008, p. 252):

\footnotetext{
"A intenção de voltar para o Japão era o primeiro sonho de todos os pais e mães que haviam emigrado. Por isso, preocupavam-se em ensinar a língua japonesa, mesmo que com professores improvisados. Para dar o apoio necessário à educação, o governo
} 
japonês providenciava livros didáticos e enviava professores, alguns dos quais se tornaram bilíngües depois de estudar em escolas normais brasileiras para poderem exercer melhor a sua função."

No caso do Brasil, esta é uma realidade verificada na maior parte dos lugares onde ocorreu a imigração japonesa, mas no Amazonas não foi totalmente assim, nem durante todo o processo histórico. Depois da Segunda Guerra, no final dos anos quarenta, a comunidade japonesa voltou a se estruturar. Enfraquecia-se o desejo de retorno ao Japão e "a maioria dos imigrantes buscava consolidar suas atividades no Brasil e enviar auxílio aos seus parentes, que passavam privações no país destruído pelo conflito mundial" (KUNIYOSHI, 2010, p. 442). É preciso entender o processo imigratório dos japoneses para o Brasil, para que se possa compreender o vácuo na transmissão da língua japonesa aos descendentes em determinadas circunstâncias. Afinal, "o ensino de língua japonesa no Brasil começou no contexto da imigração" (DOI apud MORALES, 2008, p. 139).

\section{Das motivações para a imigração}

Sendo o Japão um país insular, sua situação geográfica contribuiu na formação de uma nação fechada: o mar, que de certa forma o protegia até de uma eventual invasão de outros povos, por outro lado acarretou o isolamento da cultura. $\mathrm{O}$ primeiro contato dos japoneses com o Ocidente deu-se no século XVI, no chamado Século Cristão do Japão (1543-1639). Este contato foi interrompido pela política do sakoku, ${ }^{3}$ que significa, literalmente, "fechamento do país" Em 12 de fevereiro de 1868, com o término do Xogunato do Clã Tokugawa, que governou o Japão ao longo de exatos 265 anos (iniciou em 12 de fevereiro de 1603), o poder de fato foi retomado pelo Imperador. Este acontecimento foi denominado Restauração Meiji e propiciou a abertura dos portos que até então, ao longo do Xogunato, eram mantidos fechados. Aos poucos o Japão começava as incrementar suas relações internacionais, primeiro com os Estados Unidos e depois com outros países.

Não muito tempo depois, o Japão teve de enfrentar o problema da superpopulação: com a conseqüente necessidade de solucionar a questão do seu abastecimento, iniciaram-se os processos de emigração. Historicamente as primeiras emigrações em grandes levas ocorreram para a Manchúria, na China, para o Havaí, nos Estados Unidos, e para o Peru, na América do Sul. Todas estas emigrações foram iniciadas do final do século XIX ao início do século XX.

3. 鎖国（さこく）sakoku - A respeito dos motivos que levaram a este "fechamento", há tanto os de política interna quanto os de política externa, envolvendo sobretudo o comércio e a religião. Este fechamento não representa, porém, algo absoluto: nem todos os ocidentais foram banidos do território japonês, nem o comércio deixou de ser realizado, ainda que clandestinamente. 
No dia 18 de junho de 1908, o navio Kasato Maru aportou em Santos, trazendo os primeiros imigrantes japoneses ao Brasil. Os imigrantes desta época chegaram com a intenção de trabalhar na exploração da lavoura no Brasil e ganhar algum dinheiro principalmente na cafeicultura, com a intenção declarada de voltarem para o Japão. Isto era o fenômeno dekassegui (MORIWAKI; NAKATA, 2008, p. 16), que significa "sair da sua terra para ir à procura de trabalho rentável em outra localidade", que posteriormente aconteceria em mão inversa, com descendentes de japoneses saindo do Brasil para buscar melhores empregos e condições de vida no Japão, sobretudo na década de 80 . Já entre os imigrantes japoneses que vieram para o norte há um grupo que se destaca dos demais pela sua diferença de objetivos: os chamados kôtakusei, alunos egressos da Kôtô Takushoku Gakkô de Tóquio - donde kôtaku, com os ideogramas iniciais do nome da escola (KAWADA, 1995, p. 17)-, vinham para o Brasil tendo feito o juramento de nunca mais retornarem ao Japão. Muitos dos filhos dos kôtakusei não aprenderam a língua japonesa porque seus próprios pais desejavam a perfeita e rápida ambientação dos filhos na sociedade brasileira. Este dado é importante para esta pesquisa proposta sobre o ensino da língua japonesa no Amazonas.

Com a Segunda Guerra Mundial, ficando o Japão inimigo dos aliados e, consequentemente, do Brasil, assim como foi proibido falar e escrever em japonês, os bens dos imigrantes foram confiscados e houve muitas atitudes de discriminação, durante todo o período da guerra. Mesmo durante alguns anos após a guerra, o ensino de língua japonesa praticamente não apresentou nenhuma evolução. Moriwaki e Nakata (2008, p. 66) chamam esta época de "Período Vazio" (1946-1950).

Somente passados oito anos do término da Segunda Guerra Mundial - ou seja, em 1953 - reiniciou-se a imigração pós-guerra, denominada Retomada de Imigração No Estado do Amazonas. Chegou à Colônia Bela Vista a sua primeira leva de vinte e três famílias, em doze de setembro de 1953; cinco anos depois, em dez de novembro de 1958, chegaram dezessete famílias com cento e dezessete imigrantes para a primeira leva da Colônia Efigênio Salles. ${ }^{4}$ Em 1967. formou-se a Colônia de Cachoeira Grande, com oito famílias da Colônia Bela Vista. Estas colônias existem até hoje (CÂMARA DE COMÉRCIO E INDÚSTRIA NIPOBRASILEIRA DO AMAZONAS, 2007. p. 246).

Os primeiros imigrantes que chegaram ao Brasil, cuja intenção a priori era retornar ao Japão após juntar dinheiro, preocuparam-se muito em ensinar a língua japonesa aos seus filhos, mesmo com a determinação do Presidente Getúlio Vargas proibindo o ensino de língua japonesa no Brasil (MORIWAKI; NAKATA, 2008, p. 45). Terminada a Segunda Guerra Mundial, com a retomada da imigração começa a "reaquecer" a influência da cultura japonesa, principalmente nas regiões sul-

4. Um dos autores desta pesquisa, Ken Nishikido, é um dos imigrantes que chegaram nesta leva, com apenas sete anos de idade na época. 
-sudeste do Brasil (São Paulo e Paraná). A partir de então, a presença nipônica se encontra definitivamente fazendo parte da cultura brasileira e consequentemente a importância da sua língua começa a fazer-se mais presente na vida dos brasileiros, que são atraídos pela cultura a partir da culinária, dos esportes tradicionais, dos mangás e animês e também da língua japonesa. O Brasil é apenas um dos países onde a cultura japonesa tem sido amplamente difundida, passando "de país acostumado a assimilar características do ocidente" a país influenciador (SAKURAI, 2008, p.339).

\section{O ensino da língua japonesa}

\subsection{A educação doméstica}

Diferentemente dos imigrantes do sul do Brasil, os que imigraram para o Amazonas (tanto os que chegaram a Maués como os kôtakusei, que foram a Parintins) vieram para se estabelecer definitivamente no Brasil. Por esta razão, alguns pais tomavam a iniciativa de falar em língua portuguesa em casa e não ensinavam o japonês para não atrapalhar a evolução do aprendizado da língua portuguesa dos seus filhos. Esta iniciativa era comum, mas não era absoluta, havendo também famílias nas quais até hoje o japonês é falado no convívio diário e cujos filhos aprendem a língua japonesa.

\subsection{O ensino na comunidade}

Segundo o testemunho dos próprios imigrantes do pós-guerra, a preocupação em continuar falando sua língua de origem decorria principalmente do sentimento de preservação da cultura. Nas colônias, foram organizadas associações comunitárias, nas quais os jovens praticavam esportes tradicionais (tais como sumô, judô, beisebol etc.), ensaiavam as peças teatrais e o coral de música em língua japonesa para apresentação nos eventos culturais, publicavam jornais e boletins informativos em língua japonesa. Todavia, à medida que iam se tornando adultos, não podiam dar continuidade a estas atividades, devido ao trabalho na lavoura.

Em 1954 organizou-se um grupo de ensino de língua japonesa para os filhos dos colonos com a iniciativa da Sra. Sekiko Tsuji (na sua residência da colônia Caldeirão) e da Sra. Hisae Ideta (na sua residência da colônia Ariaú). No entanto, não se deu continuidade a este trabalho.

Em 1959, a primeira turma organizada como curso de língua japonesa foi conduzida pelo Sr. Katsuji Fujita, proveniente de São Paulo. Ele iniciou o curso na colônia Ariaú, porém, seis meses depois, com seu retorno a São Paulo, as atividades ali foram interrompidas. Em 1962, o Sr. Katsuji Fujita volta para Ariaú 
e reabre o curso, que só funciona por mais seis meses - já que depois disso o Sr. Fujita retorna a São Paulo definitivamente.

Com o avançar das gerações dos descendentes, começou-se a perceber a tendência de desinteresse progressivo por parte dos filhos e dos netos em falar a língua japonesa. Nem todos os filhos queriam ou conseguiam se casar com descendentes nipônicos e, como consequência natural, houve a ocorrência do afastamento da língua e também dos hábitos. Este desinteresse - que não é generalizado, mas uma tendência - é uma das reclamações dos imigrantes do pós-guerra (hoje, avôs e avós).

$\mathrm{Na}$ tentativa de sanar esta situação, foram organizadas dentro das comunidades, na década de setenta, as primeiras escolas de língua japonesa, cujas professoras eram donas-de-casa que se voluntariavam nas horas vagas do trabalho doméstico. No início, elas não tinham nenhum preparo didático e às vezes nem tinham os materiais apropriados. Assim, no início tinham que usar os próprios materiais didáticos provenientes do Japão (da Editora Mitsumura, por exemplo). A dificuldade não era só com os livros: na época não existiam computadores e máquinas copiadoras como temos hoje.

A reprodução era feita de forma manuscrita e impressa em mimeógrafos, quando havia este equipamento. Mesmo assim era grande a vontade de ensinar por parte das professoras (donas-de-casa na maioria) e de aprender por parte dos alunos, que eram os filhos estudantes na escola brasileira (pois os que tinham mais de 15 anos de idade, devido à avançada idade, permaneceram no trabalho de campo para ajudar a família).

Em Manaus, quem iniciou o primeiro curso de ensino de língua japonesa foi uma acadêmica nissei chamada Kazuko Kakitani, do Curso de Medicina da UA (Universidade do Amazonas, hoje UFAM). Proveniente do Estado do Paraná, de 1969 para 1970 resolveu ministrar um curso noturno de língua japonesa, tendo como alunos basicamente alguns moradores da CEJA (Casa dos Estudantes Japoneses do Amazonas), onde hoje é a sede da Associação Nipo-brasileira da Amazônia Ocidental (NIPPAKU). Com o retorno desta acadêmica para o seu Estado de origem em 1971, houve uma pequena interrupção, assumindo pouco tempo depois Hisahiko Kanda, imigrante da retomada de imigração de 1954 que ingressou na $2^{\mathrm{a}}$ leva de Colônia Bela Vista (hoje município de Iranduba).

Em 1972, uma dona-de-casa da Colônia Cachoeira Grande, Sra. Hisae Ideta, criou o curso de língua japonesa direcionado às crianças da vizinhança. Esta idéia foi acatada pela Associação Cultural Nipo-Brasileira de Manaus e abriu-se o Curso de Língua Japonesa, ocupando a dependência desocupada da antiga Casa dos Estudantes (hoje NIPPAKU) nos dias de sábado à tarde. O horário satisfazia a todos, pois os estudantes não tinham atividades escolares neste dia da semana e as donas-de-casa tinham maior disponibilidade de tempo. Nesta época chegou a 
haver mais de 150 alunos frequentando o curso, e o corpo docente também cresceu, com as senhoras Mitsuko Nozawa, Hisae Ideta, Some Kakimoto, Fumie Yamada, Sumiko Maruoka, Naoko Matsuzaki, Yoko Miyakoshi, Hiroko Goto, Adelia Suzuki, Hiroko Otonari e alguns senhores, tais como Hiroshi Nishiki e Rikio Konasugawa.

Em dezembro de 1975, o presidente da Associação dos Jovens da Colônia Efigênio de Salles, Sr. Itsuo Koba, idealiza a organização do Curso de Língua Japonesa dirigido aos jovens desta colônia. Em fevereiro de 1976 inicia-se o curso, tendo como professor o Sr. Yoshihiro Miki, que tinha sido professor no Japão e que continuou até 1978. Com o afastamento dele, o curso passou fechado pelo período de um ano. Em 1979, a Prof ${ }^{a}$ Tereza Katsuko Sato Koba, que tinha a formação de professora pela Escola Normal do Instituto Benjamim Constant e era registrada na SEDUC, assumiu também o cargo de professora de língua japonesa da comunidade, e até hoje continua. É interessante notar que, apesar da predominância de senhoras para compor o corpo docente, pois na época ser professor de língua japonesa não era uma profissão rentável, havia alguns professores empenhados com a preocupação que tinham em ensinar a língua japonesa para os seus filhos.

Até hoje, entre os educadores de língua japonesa no Brasil persiste a tendência em distinguir entre o ensino de língua de herança, para descendentes, e o ensino de japonês como língua estrangeira, para não-descendentes (MORALES, 2011, p. 43). Enquanto o primeiro sempre se manteve dentro da comunidade fechada, o segundo procurava propagar a língua japonesa no sentido mais amplo. A este ponto retornaremos um pouco mais adiante.

A instituição da Zona Franca de Manaus pelo Decreto-lei no 288 de 28 de fevereiro de 1967, que criou o modelo para implantação do Pólo Industrial de Manaus (PIM), também propiciou a intensificação da necessidade de estrutura para o ensino de língua japonesa, pelo fato de, a partir da década de setenta, algumas empresas de origem japonesa, tais como Sharp, Panasonic, Sanyo, Honda, Hitachi, entre outras, iniciarem sua implantação no PIM. Desta forma, foi criado o Curso Noturno de Língua Japonesa, destinado a atender principalmente os adultos que trabalham no Distrito Industrial, nas empresas de origem japonesa, supramencionadas, e em outras.

\subsection{O Curso de Língua Japonesa na NIPPAKU}

A Associação Nipo-Brasileira da Amazônia Ocidental, conhecida como NIPPAKU, fundada em $1^{\circ}$ de maio de 1980 , surgiu como uma instituição representativa da comunidade nikkei da Amazônia Ocidental.

O Curso de Língua Japonesa da NIPPAKU teve sua origem seguindo as duas linhas de ensino de língua japonesa já mencionadas: como língua de herança e como língua estrangeira. $\mathrm{O}$ governo do Japão, através de instituições como a 
Fundação Japão e a JICA (Japan International Cooperation Agency), oferece cursos de treinamentos de professores de língua Japonesa. Estas instituições apóiam o ensino de língua japonesa em várias partes do mundo.

Para os brasileiros não-descendentes talvez soe estranha esta posição de manter um tratamento distinto sobre o ensino de uma mesma língua. Na verdade, isto decorre do fato de a JICA ter sido originada da JAMIC (Japan Migration and Colonization), que sempre tratou dos trabalhos de apoio aos imigrantes e seus descendentes japoneses, enquanto a Fundação Japão tratava sempre de intercâmbio cultural do Japão com outros países do exterior. Daí este tratamento distinto no ensino de língua japonesa no Brasil.

Tanto a JICA quanto a Fundação Japão tiveram papel fundamental para a formação do corpo docente do Curso de Língua Japonesa da NIPPAKU e das escolas das comunidades circunvizinhas. Desde a década de oitenta, a JICA e a Fundação Japão propiciaram o Curso de Treinamento aos Professores de Língua Japonesa. Segundo o registro da Associação Nipo-Brasileira da Amazônia Ocidental, de 1980 a 1999 nove professores estiveram no Japão participando do Curso de Treinamento (com duração de dois meses) pela JICA; de 1987 a 2006, dez professores participaram do Curso de Treinamento (também de dois meses) pela Fundação Japão.

Num esforço de ampliar o alcance de seu apoio aos professores da região norte, a JICA enviou professores voluntários que até a presente data trabalham para atender às instituições da Amazônia Ocidental, no sentido de orientar e elevar o nível de capacidade didática e de conhecimento da língua japonesa propriamente dita dos professores daqui. Foram oito voluntários que atuaram em média dois anos cada, a partir do ano de 1987 até o presente. O voluntário sênior atual, Prof. Toshimi Tsuruta, por exemplo, além de organizar eventos e benkyôkai com os professores da Associação Nipo-Brasileira da Amazônia Ocidental, em Manaus, visita periodicamente outras cidades, tais como Porto Velho (RN), Parintins (AM), Rio Branco (AC), Boa Vista (RR), onde há instituições menores de ensino da língua japonesa, as quais também recebem o apoio da JICA através do voluntário enviado.

Com esse suporte recebido, somado ao grande interesse dos não-descendentes, houve o crescimento vertiginoso do curso, principalmente a partir de 2005 , em que houve mais de trezentos alunos matriculados por período (semestral); em 2006, registrou-se mais de 400 alunos matriculados por período; em 2007, atingiu-se 500 alunos matriculados por período e desde 2008 se mantém no nível de 600 a 700 alunos matriculados por período.

Hoje, no Estado do Amazonas, há onze instituições que ensinam a língua japonesa, das quais dez (NIPPAKU, UFAM, UEA, FUCAPI, Alternativo de Petrópolis, Efigênio Sales, Nemunoki Gakuen, Escola Josephina de Melo, Escola Japonesa e Kumon) se encontram em Manaus e uma em Parintins, totalizando mais de mil e duzentos estudantes dedicando-se ao estudo da língua japonesa. 
Infelizmente, uma das mais antigas, que era o Curso da Colônia Ariaú (que depois passou a se denominar comunidade de Asahi), atualmente encontra-se fechada por falta de professor.

\subsection{Ensino de japonês em nível superior: o Curso de Letras - Japonês da UFAM}

Os estudos de Letras - Língua e Literatura Japonesa no Brasil tiveram início em meados da década de sessenta, no Estado de São Paulo, onde está a maior comunidade nikkei do Brasil. A USP (Universidade de São Paulo) inaugurou seu curso de Letras - Japonês com duração de quatro anos, em 1964. Depois da USP, outras universidades foram aos poucos abrindo espaço para a língua japonesa em nível superior, como se vê no quadro abaixo:

\begin{tabular}{|l|c|l|}
\hline Universidade & Início & Duração do curso \\
\hline Universidade de São Paulo (USP) & 1964 & 4 anos \\
\hline Universidade Federal do Rio de Janeiro (UFRJ) & 1979 & 4 anos \\
\hline Universidade Federal do Rio Grande do Sul (UFRGS) & 1986 & 4 anos e meio \\
\hline Universidade Estadual Paulista (UNESP) & 1992 & 4 anos \\
\hline Universidade de Brasília (UnB) & 1997 & 4 anos e meio \\
\hline Universidade Estadual do Rio de Janeiro (UERJ) & 2003 & 4 anos \\
\hline Universidade Federal do Paraná (UFPR) & 2009 & 4 anos e meio \\
\hline Universidade Federal do Amazonas (UFAM) & 2011 & 4 anos e meio \\
\hline
\end{tabular}

Como a única universidade do norte do Brasil a oferecer o curso de Letras - Japonês atualmente, a Universidade Federal do Amazonas deve potencializar o ensino da língua associado ao ensino da literatura e da cultura japonesa baseando-se nos pilares da universidade: ensino, pesquisa e extensão. As atividades de ensino, que são sempre as mais evidentes, devem vir acompanhadas de iniciativas de pesquisa - nas quais se insere o presente trabalho - e de extensão - fazendo fluir para a comunidade o conhecimento que se produz internamente. Neste sentido, o curso (corpo docente e discente) reúne forças no sentido de participar de maneira efetiva da história do ensino da língua japonesa no Amazonas.

\section{Considerações finais}

A história do ensino da língua japonesa está entrelaçada à própria história da imigração japonesa. No Estado do Amazonas, a transmissão da língua, tanto na 
modalidade sucessória quanto na modalidade de difusão, ocorre segundo as motivações dos imigrantes - ficar ou ir embora - e sofre, como no restante do Brasil, momentos de baixa considerável no período relativo à Segunda Guerra Mundial.

A pesquisa prossegue através do levantamento de documentos (fotos, atas, publicações etc.) que revelem algo a respeito das atividades de ensino de língua japonesa no Amazonas. De acordo com os objetivos propostos no projeto, o resultado almejado é uma cronologia destas atividades de ensino, bem como a verificação das diferenças entre os cursos que ministram aulas de língua japonesa, o seu público-alvo, os seus resultados.

Numa época em que estudar japonês "virou moda", especialmente entre os jovens, por influência de mangás, animes e afins, o número de instituições de ensino da língua japonesa cresce em quantidade e representatividade, buscando também o crescimento na qualidade através de programas de aperfeiçoamento oferecidos pelo governo japonês e da formação de professores através do recém-criado curso de Letras - Japonês da Universidade Federal do Amazonas. É preciso registrar a trajetória destas instituições, bem como a trajetória das primeiras iniciativas isoladas que, apesar dos percalços, cumpriram seu objetivo de difundir, ainda que em menor escala, a língua e a cultura japonesa.

\section{Referências Bibliográficas}

ARAI, J.; HIRASAKI, C. 100 Anos de Imigração Japonesa no Brasil. São Paulo: Bunkyo Imprensa Oficial, 2008.

CÂMARA DE COMÉRCIO E INDÚSTRIA NIPO-BRASILEIRA DO AMAZONAS. Manaus: Edição comemorativa do $20^{\circ}$. Aniversário. São Paulo: Topan-Press, 2007

KAWADA, Takuya. Histórico da Imigração Japonesa no Estado do Amazonas. Manaus: FIEAM, 1995.

KUNIYOSHI, C. Fraturas e recomposições: o prazer de ser japonês e brasileiro no ocidente e no oriente. In: CARNEIRO, M.L.T.; TAKEUCHI, M.Y. (org.) Imigrantes japoneses no Brasil: trajetória, imaginário e memória. São Paulo: EDUSP, 2010.

MORALES, Leiko Matsubara. Escolas comunitárias Nihongo-gakkô-um legado da imigração japonesa no Brasil. In: Anais do VI Congresso Internacional de Estudos Japoneses no Brasil e XIX Encontro Nacional de Professores Universitários de Língua, Literatura e Cultura Japonesa. Rio de Janeiro: Gráfica da Universidade Federal do Rio de Janeiro, 2008.

O ensino de (língua de) herança. In: MORALES, L.M. (org.) Ensino e aprendizagem da língua japonesa no Brasil: um convite à reflexão sobre a prática do ensino. São Paulo: Fundação Japão, 2011.

MORIWAKI, R.; NAKATA, M. História de Ensino da Língua Japonesa no Brasil. São Paulo: Editora da UNICAMP, 2008. 
SÁ, M.E.B. de. A imigração japonesa no Amazonas à luz da Teoria das Relações Internacionais. Manaus: EDUA, 2010.

SAKURAI, C. Os japoneses. São Paulo: Contexto, 2008. 